\title{
High blood pressure in older subjects with cognitive impairment
}

\section{L'ipertensione arteriosa nell'anziano con deficit cognitivo}

\author{
Enrico Mossello, David Simoni \\ Research Unit of Medicine of Ageing, Department of Experimental and Clinical Medicine, \\ University of Florence \\ Azienda Ospedaliero-Universitaria Careggi, Florence, Italy
}

\begin{abstract}
High blood pressure and cognitive impairment often coexist in old age, but their pathophysiological association is complex. Several longitudinal studies have shown that high blood pressure at midlife is a risk factor for cognitive impairment and dementia, although this association is much less clear in old age. The effect of blood pressure lowering in reducing the risk of dementia is only borderline significant in clinical trials of older subjects, partly due to the insufficient follow-up time. Conversely, dementia onset is associated with a decrease of blood pressure values, probably secondary to neurodegeneration. Prognostic effect of blood pressure values in cognitively impaired older subjects is still unclear, with aggressive blood pressure lowering being potentially harmful in this patients category.

Brief cognitive screening, coupled with simple motor assessment, is warranted to identify frail older subjects who need a more cautious approach to antihypertensive treatment. Values obtained with ambulatory blood pressure monitoring seem more useful than clinical ones to predict the outcome of cognitively impaired older subjects. Future studies should identify the most appropriate blood pressure targets in older subjects with cognitive impairment.
\end{abstract}

Corresponding author: Enrico Mossello, Research Unit of Medicine of Ageing, Department of Experimental and Clinical Medicine, University of Florence, Azienda Ospedaliero-Universitaria Careggi, Viale G. Pieraccini 6, 50139 Firenze, Italy. E-mail: enrico.mossello@unifi.it

Key words: High blood pressure; cognitive impairment; hypertension; dementia; antihypertensive agents.

Parole chiave: Ipertensione; deficit cognitivo; demenza; trattamento antiipertensivo.

Received for publication: 21 March 2016

Accepted for publication: 25 March 2016

(C) Copyright E. Mossello and D. Simoni, 2015

Tipografia PI-ME Editrice, Italy

Monaldi Archives for Chest Disease Cardiac Series 2015; 84:730

doi: 10.4081/monaldi.2015.730

This article is distributed under the terms of the Creative Commons Attribution Noncommercial License (by-nc 4.0) which permits any noncommercial use, distribution, and reproduction in any medium, provided the original author(s) and source are credited.

\section{Riassunto}

Ipertensione arteriosa e decadimento cognitivo spesso coesistono in età avanzata, sebbene la loro associazione sia complessa dal punto di vista fisiopatologico. Diversi studi longitudinali hanno mostrato che elevati valori pressori in età adulta rappresentano un fattore di rischio per decadimento cognitivo e demenza, sebbene tale associazione sia molto meno chiara in età avanzata. L'effetto della terapia antiipertensiva è risultato ai limiti della significatività statistica nel ridurre il rischio di demenza negli studi di intervento su soggetti anziani, in parte a causa della durata insufficiente del follow-up. D'altra parte, l'insorgenza di demenza è associata con una riduzione dei valori pressori, probabilmente secondaria alla neurodegenerazione. L'effetto prognostico dei valori pressori in anziani con decadimento cognitivo non è stato ancora chiarito, in presenza di un possibile effetto dannoso di un trattamento antiipertensivo aggressivo in questa categoria di pazienti. Un breve screening cognitivo, associato con una semplice valutazione motoria, è raccomandato per identificare gli anziani fragili, che necessitano di un approccio più cauto alla terapia antiipertensiva. I risultati del monitoraggio della pressione arteriosa nelle 24 ore sembrano più utili della misurazione clinica per predire la prognosi degli anziani cognitivamente compromessi. Studi futuri dovrebbero identificare gli obiettivi pressori più appropriati nel trattamento di anziani con decadimento cognitivo.

\section{Introduction}

The importance of blood pressure and cognitive impairment in old age is highlighted by several reasons. The main reason is that high blood pressure (HBP) and different forms of cognitive impairment are highly prevalent and often associated in old age. According to available data, $54 \%$ of older males and $57 \%$ of older females have HBP[1]. Dementia affects $6-8 \%$ of subjects aged $60+$ years and as much as $25 \%$ of those aged $85+[2]$, whereas mild cognitive impairment (MCI), a less severe form of cognitive decline that may herald the development of overt dementia, is observed in a large proportion of subjects over 65 , with prevalence estimates of about $25 \%$ [3].

HBP often coexists with cognitive impairment in old age, consistently with data which have identified it as a risk factor for cognitive impairment and dementia[4]. This has been shown clearly for vascular dementia, which is characterized by macro- and/or microvascular lesions, whose main risk factor is represented by HBP [5]. Yet the pathophysiological association between blood pressure and cognition during life-course is complex and varies in strength and direction with time, as discussed below. Most importantly, subjects in advanced age have 
both highest cardiovascular risk and potentially severe adverse effects from antihypertensive drugs (AHD) [6]. This is even clearer with regard to the potential role of AHD in preventing cognitive decline, which is far less established in comparison with other health related outcomes [7], with some observational data [8] even showing a reverse association between blood pressure and dementia risk in older subjects on AHD. Even less is known about the prognostic role of HBP and AHD when cognitive impairment and dementia are already present.

Available clinical evidence regarding this issue is synthetized below, and suggestions regarding the role of cognitive assessment in decisions regarding antihypertensive treatment strategies are given at the end.

\section{High blood pressure and risk of cognitive impairment/dementia during the life course}

Early cross-sectional studies searching for the association between $\mathrm{BP}$ and cognition have given inconsistent results, as all kind of association have been identified in different samples, including positive, negative, U-shaped, and also no association [4].

Longitudinal studies have made the picture clearer, as the majority, albeit not the total, of them, have identified an association of HBP with subsequent cognitive impairment and dementia [4]. This prognostic association was clearly identified for high systolic blood pressure (SBP) at midlife, predicting dementia and Alzheimer's disease after a 20-year follow-up time [9]. A similar association was also observed at age 70, with HBP being associated with the risk of both dementia and Alzheimer's disease 15 years later [10]. Yet more complex [11] and even reverse association [12] between blood pressure values and risk of dementia in old age have been observed over the age of 75 .

\section{Efficacy of AHD in reducing the risk of dementia in old age: evidence based data}

None of the randomized controlled trials which have shown the preventive efficacy of AHD in old age included cognitive impairment or dementia as primary outcome. This is important for data interpretation, as the sample size and, most notably, the follow-up time needed to identify such an effect is likely greater from what is needed from cardiovascular outcomes. Syst-Eur was the only single study which have shown the ability of AHD in reducing dementia risk significantly, and this was observed only in the 4-year open label extension [13]. The meta-analysis of HYVET-Cog together with Syst-Eur, SHEP, and PROGRESS results have identified a borderline significant $13 \%$ relative risk reduction in AHD arm vs. placebo, thus supporting a potential preventive role in a context of wide heterogeneity of effects [7].

\section{Modulators of preventive role of AHD age and functional status}

Due to the inconsistency of results regarding the prognostic role of $\mathrm{BP}$ with regard to cognitive impairment and dementia in old age the identification of subgroup of subjects with different features seems clinically relevant.

One of the main modulating factors identified is age, as shown by the meta-analysis of two Dutch epidemiological studies: the Rotterdam study, including subjects aged 55-84 and the Leiden 85-Plus study, including subjects aged 85 at baseline. While higher SBP values were as- sociated with a greater risk of subsequent cognitive decline in the 6574 cohort, BP seemed to have a neutral effect between 75 and 84, and the opposite association was observed in subjects aged 85 [14].

Moreover, in Leiden 85-Plus study an analysis stratified for baseline disability was performed, showing a much greater association between lower systolic BP values and subsequent cognitive impairment in subjects with ongoing disability status [15].

An analysis from the National Health and Nutrition Examination Survey (NHANES) supports a role for motor performance as a powerful modulator of BP associated mortality risk, irrespectively of cognitive impairment. In fact, in a cohort of 2340 older subjects (mean age 74), the association between BP and 7-year mortality varied markedly among subjects, according to their ability to walk $6 \mathrm{~m}$ as fast walkers $(\geq 0.8 \mathrm{~m} / \mathrm{sec})$, slow walkers $(<0.8 \mathrm{~m} / \mathrm{sec})$ or unable to complete the task. In fact, while high SBP was associated with increased mortality among fast walkers, the association disappeared among slow walkers and was reverted among subjects unable to walk, who had a greater risk associated with low values of SBP and DBP [16].

Therefore, available evidence supports the hypotheses that advanced age per se and/or functional impairment might affect the association between blood pressure values and prognosis.

\section{The effect of dementia on BP values: reverse causation}

While the prognostic role of high BP in regard to dementia in old age is debated, several studies have shown an effect of dementia onset in reducing $\mathrm{BP}$ values. Therefore, in life-course studies, high $\mathrm{BP}$ values have been associated with increased dementia risk after decades, while cognitive impairment is followed by BP values decline [17]. As dementia severity and brain atrophy are correlated with low BP values over 85, this phenomenon is thought to be secondary to neurodegeneration [18]. Therefore, a window of opportunity is depicted, during which AHD have the potential to decrease dementia risk; conversely dementia onset represents a risk factor of hypotension, calling for de-intensification of treatment to reduce the risk of adverse events.

\section{AHD in subjects with ongoing cognitive impairment/dementia: risks and benefits}

Subjects with cognitive impairment represent a subpopulation at high risk for cerebrovascular damage and brain hypoperfusion, making the effect of AHD on cognitive function difficult to foresee. In fact data are not clear-cut. One study of 1385 subjects with mild cognitive impairment (mean age 73.6, baseline MMSE 28/30), has found a faster progression of cognitive decline over 2 years among subjects with repeated detection of high BP ( $\geq 140 / 90 \mathrm{mmHg}$ ) [19]. In keeping with these data, subjects with mild cognitive impairment (mean age 67.8, baseline MMSE 26/30) have been found to have an increased risk of conversion to Alzheimer's disease after five years, while AHD reduced the risk [20]. Moreover, in subjects with Alzheimer's disease an association between higher SBP values and greater cognitive decline was observed in one study [21], but not in another [22]. A recent study conducted with ambulatory blood pressure monitoring (ABPM) in a sample of 172 older subjects with dementia or mild cognitive impairment (mean age 79, MMSE 22/30) has observed an increased risk of cognitive decline after 9 months among subjects with lower mean daytime SBP (<129 mmHg) actively treated with AHD [23]. Another recent study of 141 subjects with mild cognitive impairment (mean age 74) 
has observed an independent association between orthostatic hypotension and increased risk for conversion to dementia after 2 years [24]. Therefore, the presence of mild cognitive impairment might be a caveat for possible detrimental effects of excessive blood pressure lowering, at least among oldest old and for subjects with orthostatic hypotension and overt dementia. ABPM seems to be more useful than clinical measure in predicting the cognitive detrimental effects of hypotension.

\section{The role of cognitive assessment in deciding regarding antihypertensive treatment}

Limitations in activities of daily living and cognitive impairment frequently occur during old age. Several longitudinal data have associated HBP with risk of disability onset [25]. Together with increased stroke risk, the increased risk of cognitive impairment onset linked with microvascular cerebral lesions, also without acute cerebrovascular events, might explain this association [26]. Of notice, the extent of brain microvascular changes has been associated with extra-cerebral end organ damages in HBP, including chronic kidney damage [27], increased left ventricular mass [28] and retinal microvascular changes [29].

Therefore, the assessment of cognitive status in older hypertensives subjects have two different aims:

1) to have an indirect, easy obtainable estimate of brain end organ damage associated with high BP;

2) to assess the prognostic role of BP values in the context of the biological age of the single subject, including the presence of cognitive impairment.

Several short measures of cognitive status among older subjects exist and can be used in clinical practice. Among such measures, Mini Mental State Examination (MMSE) [30] is one of the best known and probably represents a "gold standard" for brief cognitive assessment, due to its widespread use both in clinical and in research setting all over the world, the ability to reliably identify dementia and stage its severity and the possibility to follow-up patients over time [31]. The administration of the test is 5-10 minutes long, depending on patient's cognitive status, and includes items testing orientation to space and time, words repetition and recall, attention and calculation, word finding, phrase repetition, comprehension of spoken and written language, and constructional praxis. The total score is included between 0 and 30 , with higher values representing better cognitive function and 24 being the most widely adopted cut-off for dementia. Locally validated rules exist to adjust the score for age and education. While this instrument will probably be widely adopted in a geriatric facility, it will be probably felt as too time consuming in a cardiologic setting or in a typical hypertension clinic. A suitable, less time-consuming alternative for cognitive screening is the Mini-Cog [32], which requests only a 2 minute assessment, including the recall of the 3 words, similar to the MMSE, and the drawing of a clock. The scoring of the test is straightforward, as shown in Figure 1.

To reduce the risk of false positives, it is recommended to corroborate the suspect of dementia, as resulting from Mini-Cog, with

1. report of cognitive impairment by patient himself and/or relatives, in agreement with accepted criteria for dementia and Mild Cognitive Impairment [33];

2. impairment in instrumental activities of daily living, especially those not requiring preserved physical performance, such as use of telephone, handling medications and finances, which appears to be fairly specific for dementia [34].

Since 2013, European [35] and US [36] guidelines have acknowledged different cut-offs and target values for antihypertensive drugs treatment in old age. Moreover, European guidelines leave to the clinical judgment of the treating physician the choice regarding "frail" older subjects. In fact, several studies in most recent years have

Figure 1. Mini-Cog Test [32]: administration and scoring

1. Ask the patient to repeat 3 semantically unrelated words

2. Ask the patient to draw a clock

$\checkmark$ Draw a circle

$\checkmark$ Add the numbers

$\checkmark$ Set the time on 11:10

3. Ask the patient to recall the previously repeated words

Clock Drawing Test (CDT) is normal if all numbers are present in the right sequence and position and clock's hands are in the right position. Test is scored according to the following algorithm:

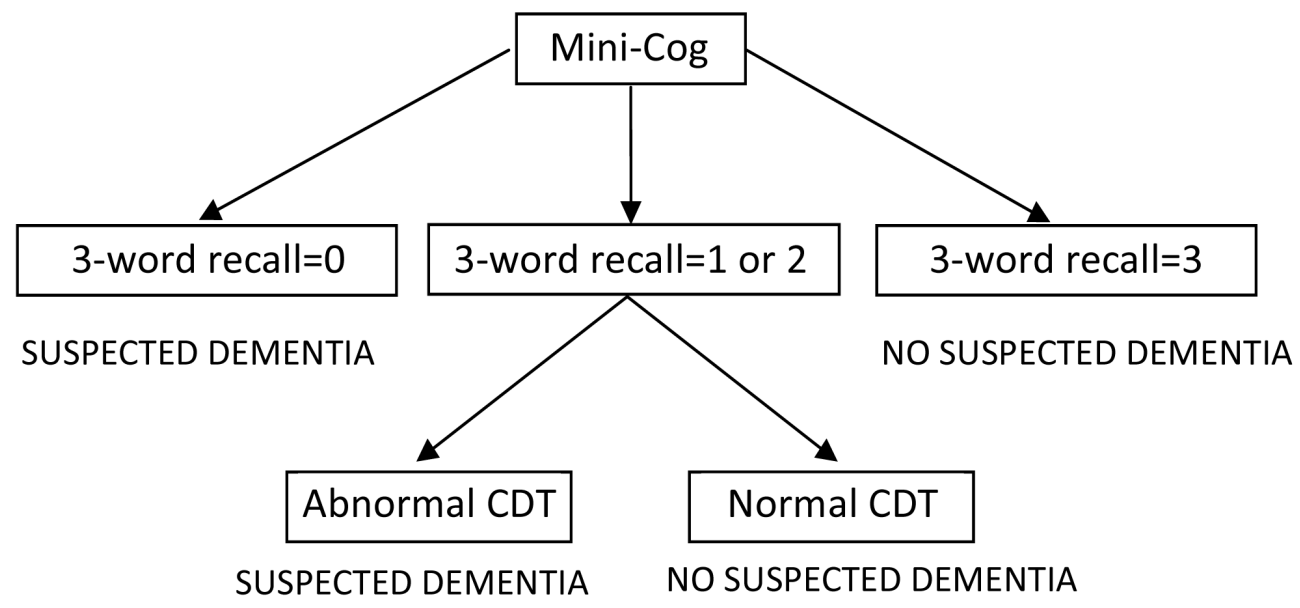


pointed out at a role for "frailty" in increasing the risk associated with antihypertensive treatment among elderly subjects [37].

In geriatric research frailty is conceptualized as a physiological syndrome characterized by decreased functional reserve and diminished resistance to stressors, causing vulnerability to adverse health outcomes, including disability and death [38]. While frailty should be reliably identified with a comprehensive geriatric assessment, identifying multiple physical, mental and social impairments whose accumulation may ultimately lead to the increased vulnerability status [39], rapid screener for this condition are often needed In clinical practice due to time and resource constraints. Therefore simple clinical tools have been operationalized to detect frailty with sufficient sensitivity and specificity [40], including instruments based on lower extremity performance, that seem to be the most useful for this purpose [41]. This seems clinically significant also in the perspective of HBP treatment, in agreement with the above cited data showing an association between high SBP and increased mortality among fast walkers, no association between blood pressure and mortality among slow walkers and association between low blood pressure and increased mortality risk among subjects unable to walk [16].

Moreover, in keeping with recent data suggesting an association between low daytime SBP, as measured with ABPM, and greater cognitive decline among cognitively impaired older subjects treated with AHD [23], a less aggressive antihypertensive treatment might be warranted also in this category of patients. Yet, a treatment discontinuation randomized trial of 385 older subjects $75+$ with mild cognitive decline (mean age 81, MMSE 26/30) was recently published. Subjects were included if they took at least one antihypertensive drug and SBP was $\leq 160 \mathrm{mmHg}$. After 16 weeks SBP went from $148.8 \mathrm{mmHg}$ to 154.2 $\mathrm{mmHg}$, but no positive effect was evident on cognitive function, psychological status or daily functioning [42].

On the whole, the presence of cognitive and motor impairment might be a useful marker of increased vulnerability to AHD, although specific cut-off values for different patients categories have to be identified. Conversely, the recently published SPRINT trial suggests that, in older patients without severe disability, cognitive impairment, cerebrovascular disease and diabetes mellitus, lower blood pressure are associated with better outcomes. These factors suggest that vascular risk factor prevention, including antihypertensive treatment, should be personalized in older subjects, and should include the measure of simple frailty indexes, with a possible referral of the most complex cases to a comprehensive geriatric assessment [43].

Further studies of treatment de-intensification are warranted, with the aim of identifying the role of different BP measures (clinical $v s$ ambulatory) and different BP targets for specific subgroups of frail older subjects, with a specific focus on cognitive impairment.

\section{References}

1. Go AS, Mozaffarian D, Roger VL, et al. Heart disease and stroke statistics - 2014 update: a report from the American Heart Association. Circulation 2014;129:e28-e292.

2. Prince M, Bryce R, Albanese E, et al. The global prevalence of dementia: a systematic review and metaanalysis. Alzheimers Dement 2013;9:63-75.

3. Ward A, Arrighi HM, Michels S, Cedarbaum JM. Mild cognitive impairment: disparity of incidence and prevalence estimates. Alzheimers Dement 2012;8:14-21.

4. Qiu C, Winblad B, Fratiglioni L. The age-dependent relation of blood pressure to cognitive function and dementia. Lancet Neurol $2005 ; 4: 487-99$.
5. Román GC, Tatemichi TK, Erkinjuntti T, et al. Vascular dementia: diagnostic criteria for research studies. Report of the NINDSAIREN International Workshop. Neurology 1993;43:250-60.

6. Jansen S, Bhangu J, de Rooij S, et al. The Association of Cardiovascular Disorders and Falls: A Systematic Review. J Am Med Dir Assoc 2015.

7. Peters R, Beckett N, Forette F, et al. Incident dementia and blood pressure lowering in the Hypertension in the Very Elderly Trial cognitive function assessment (HYVET-COG): a double-blind, placebo controlled trial. Lancet Neurol 2008;7:683-9.

8. Ruitenberg A, Skoog I, Ott A, et al. Blood pressure and risk of dementia: results from the Rotterdam study and the Gothenburg H-70 Study. Dement Geriatr Cogn Disord 2000;12:33-9.

9. Kivipelto M, Helkala EL, Laakso MP, et al. Midlife vascular risk factors and Alzheimer's disease in later life: longitudinal, population based study. BMJ 2001;322:1447-51.

10. Skoog I, Lernfelt B, Landahl S, et al. 15-year longitudinal study of blood pressure and dementia. Lancet 1996;347:1141-5.

11. Qiu C, von Strauss E, Fastbom J, et al. Low blood pressure and risk of dementia in the Kungsholmen project: a 6-year follow-up study. Arch Neurol 2003;60:223-8.

12. Verghese J, Lipton RB, Hall CB, et al. Low blood pressure and the risk of dementia in very old individuals. Neurology 2003;61:1667-72.

13. Forette F, Seux ML, Staessen JA, et al. The prevention of dementia with antihypertensive treatment: new evidence from the Systolic Hypertension in Europe (Syst-Eur) study. Arch Intern Med 2002;162:2046-52.

14. Euser SM, van Bemmel T, Schram MT, et al. The effect of age on the association between blood pressure and cognitive function later in life. J Am Geriatr Soc 2009;57:1232-7.

15. Sabayan B, Oleksik AM, Maier AB, et al. High blood pressure and resilience to physical and cognitive decline in the oldest old: the Leiden 85-plus Study. J Am Geriatr Soc 2012;60:2014-9.

16. Odden MC, Peralta CA, Haan MN, Covinsky KE. Rethinking the association of high blood pressure with mortality in elderly adults: the impact of frailty. Arch Intern Med 2012;172:1162-8.

17. Joas E, Backman K, Gustafson D, et al. Blood pressure trajectories from midlife to late life in relation to dementia in women followed for 37 years. Hypertension 2012;59:796-801.

18. Skoog I, Andreasson LA, Landahl S, Lernfelt B. A population-based study on blood pressure and brain atrophy in 85-year-olds. Hypertension 1998;32:404-9.

19. Goldstein FC, Levey AI, Steenland NK. High blood pressure and cognitive decline in mild cognitive impairment. J Am Geriatr Soc 2013;61:67-73.

20. Li J, Wang YJ, Zhang M, et al. Vascular risk factors promote conversion from mild cognitive impairment to Alzheimer disease. Neurology 2011;76:1485-91.

21. Mielke MM, Rosenberg PB, Tschanz J, et al. Vascular factors predict rate of progression in Alzheimer disease. Neurology 2007;69:1850-8.

22. Helzner EP, Luchsinger JA, Scarmeas N, et al. Contribution of vascular risk factors to the progression in Alzheimer disease. Arch Neurol 2009;66:343-8.

23. Mossello E, Pieraccioli M, Nesti N, et al. Effects of low blood pressure in cognitively impaired elderly patients treated with antihypertensive drugs. JAMA Intern Med 2015;175:578-85.

24. Hayakawa T, McGarrigle CA, Coen RF, et al. Orthostatic blood pressure behavior in people with mild cognitive impairment predicts conversion to dementia. J Am Geriatr Soc 2015;63:1868-73.

25. Lawes CM, Vander Hoorn S, Rodgers A, Hypertension ISo. Global burden of blood-pressure-related disease, 2001. Lancet 2008; 371:1513-8. 
26. Hajjar I, Quach L, Yang F, et al. Hypertension, white matter hyperintensities, and concurrent impairments in mobility, cognition, and mood: the Cardiovascular Health Study. Circulation 2011; 123:858-65.

27. Makin SD, Cook FA, Dennis MS, Wardlaw JM. Cerebral small vessel disease and renal function: systematic review and meta-analysis. Cerebrovasc Dis 2015;39:39-52.

28. Sierra C, de la Sierra A, Paré JC, et al. Correlation between silent cerebral white matter lesions and left ventricular mass and geometry in essential hypertension. Am J Hypertens 2002;15:507-12.

29. Yau PL, Hempel R, Tirsi A, Convit A. Cerebral white matter and retinal arterial health in hypertension and type 2 diabetes mellitus. Int J Hypertens 2013;2013:329602.

30. Folstein MF, Folstein SE, McHugh PR. "Mini-mental state". A practical method for grading the cognitive state of patients for the clinician. J Psychiatr Res 1975;12:189-98.

31. Mossello E, Boncinelli M. Mini-mental state examination: a 30-year story. Aging Clin Exp Res 2006;18:271-3.

32. Borson S, Scanlan J, Brush M, et al. The mini-cog: a cognitive 'vital signs' measure for dementia screening in multi-lingual elderly. Int J Geriatr Psychiatry 2000;15:1021-7.

33. Albert MS, DeKosky ST, Dickson D, et al. The diagnosis of mild cognitive impairment due to Alzheimer's disease: recommendations from the National Institute on Aging-Alzheimer's Association workgroups on diagnostic guidelines for Alzheimer's disease. Alzheimers Dement 2011;7:270-9.

34. Cromwell DA, Eagar K, Poulos RG. The performance of instrumental activities of daily living scale in screening for cognitive impairment in elderly community residents. J Clin Epidemiol 2003;56:131-7.

35. Mancia G, Fagard R, Narkiewicz K, et al. 2013 ESH/ESC guidelines for the management of arterial hypertension: the Task Force for the
Management of Arterial Hypertension of the European Society of Hypertension (ESH) and of the European Society of Cardiology (ESC). Eur Heart J 2013;34:2159-219.

36. James PA, Oparil S, Carter BL, et al. 2014 Evidence-Based Guideline for the Management of High Blood Pressure in Adults. Report from the Panel Members Appointed to the Eighth Joint National Committee (JCN 8). JAMA 2014;311:507-20.

37. Muller M, Smulders YM, de Leeuw PW, Stehouwer CD. Treatment of hypertension in the oldest old: a critical role for frailty? Hypertension 2014;63:433-41.

38. Walston J, Hadley EC, Ferrucci L, et al. Research agenda for frailty in older adults: toward a better understanding of physiology and etiology: summary from the American Geriatrics Society/National Institute on Aging Research Conference on Frailty in Older Adults. J Am Geriatr Soc 2006;54:991-1001.

39. Clegg A, Young J, Iliffe S, et al. Frailty in elderly people. Lancet 2013;381:752-62.

40. Clegg A, Rogers L, Young J. Diagnostic test accuracy of simple instruments for identifying frailty in community-dwelling older people: a systematic review. Age Ageing 2015;44:148-52.

41. Minneci C, Mello AM, Mossello E, et al. Comparative study of four physical performance measures as predictors of death, incident disability, and falls in unselected older persons: the insufficienza Cardiaca negli Anziani Residenti a Dicomano Study. J Am Geriatr Soc 2015;63:136-41.

42. Moonen JE, Foster-Dingley JC, de Ruijter W, et al. Effect of Discontinuation of Antihypertensive Treatment in Elderly People on Cognitive Functioning-the DANTE Study Leiden: A Randomized Clinical Trial. JAMA Intern Med 2015.

43. Mossello E. Targeting Vascular risk factors in older adults: from polypill to personalized prevention. JAMA Intern Med 2015;175: 1949-50. 